\title{
Performance Enhancement of Wound Rotor Induction Motor by VSI with Dynamic Capacitor Controlled Rotor Circuit
}

\author{
K.Ranjith kumar \\ Senior Lecturer \\ Dept.of Electrical Engineering \\ Govt College of Technology, \\ Coimbatore, Tamil Nadu, India
}

\author{
Dr.S.Palaniswami \\ Professor \\ Dept.of Electrical Engineering \\ Govt College of Technology, \\ Coimbatore, Tamil Nadu, India
}

\author{
K.Priyadharsini \\ PG Scholar \\ Power Electronics and Drives \\ Govt College of Technology, \\ Coimbatore, Tamil Nadu, India
}

\begin{abstract}
The paper proposes a novel method for improving performance of a Three Phase wound rotor induction motor using an indirect reactive current control scheme in the rotor. A 3 phase VSI with a dynamic capacitor is connected in the rotor circuit for controlling the reactive current in the rotor. The dynamic capacitor is an $\mathrm{H}$ bridge switch with a capacitor in which the duty ratio of the $\mathrm{H}$ bridge circuit is varied in order to change the capacitance value dynamically. The proposed technique is simulated in MATLAB 7.6 / Simulink environment. The result that obtained from the proposed method is compared with secondary impedance control scheme and the performance parameters such as the torque, power factor and efficiency are obtained. In addition to improving performances, as the proposed method uses only one capacitor in the rotor where as against three capacitors are used in the rotor impedance control scheme. The result has shown improved performance and cost effective by the proposed scheme.
\end{abstract}

\section{General Terms}

Performance, Verification, Comparison

\section{Keywords:}

Wound rotor Induction motor, VSI with dynamic capacitor, rotor impedance control, H-bridge Capacitor switch

\section{INTRODUCTION}

The utility of induction motors are more than $50 \%$ of the total electric energy generated worldwide. A small improvement in efficiency would significantly save the total electric energy. Hence, it is important to optimize the efficiency of motor drive systems if significant energy savings are to be obtained. The induction motor(IM), especially the squirrel-cage type, is widely used in electrical drives and is responsible for most of the energy consumed by electric motors [3].

If equal resistances are included in each secondary phase of three phase induction motor, the speed decreases as the secondary resistances increases. A study is made in which the impedances to be connected into the secondary circuits of the motor are not resistors but passive impedances. [2]

A novel concept for obtaining various Torque-speed characteristics from a wound rotor induction motor by operating such a motor close to its resonance have been introduced. Being essentially a one speed device, the induction motor produces maximum torque when the rotor resistance is approximately equal to the slip times the rotor reactance.
$\mathrm{X}_{\mathrm{r}}$ is normally much greater than $\mathrm{R}_{\mathrm{r}}$, and the machine is hardly ever operated at the maximum torque conditions continuously. In order to get the resonant condition, a capacitive reactance has been introduced in the rotor circuit for cancelling the inductive reactance of the rotor circuit. Speed control of an induction motor is possible by having a resonant rotor circuit, which is adjusted according to the slip frequency. The main drawback of this method is that a wound rotor machine is more costly than a squirrel-cage machine and reactive components capable of conducting large currents and withstanding high voltages are relatively expensive. Also, some form of a control system will be needed to carry out a reactive component switching strategy [3]

In order to overcome the problem faced in [3], a novel system has been presented for the control of the phase difference between voltage and current in inductive circuits, using a switched capacitor. The system provides good results, even if the parameters of the circuit are unknown. The power factor control is one of the main directions in power electronics research. Lately, the work in this field has been facilitated by the development of the buck, boost or buck-boost converters using soft switching techniques (multiresonant or quasi-resonant versions). Novel control strategies based on concepts such as: delta modulation or fuzzy logic has been developed [4]

The switched capacitor concept [4] has been adopted with the use of non-resistive secondary control of an induction motor to improve the efficiency, power factor and torque. It utilizes the concept of switched capacitor which makes use of four thyristors which forms a H-bridge circuit and a single capacitor for each rotor phase. The complementary switch pairs are switched using a PWM strategy [5]. The main drawback of this method is the usage of more number of switches and three capacitors in the rotor circuit which are costly.

Many techniques are available for control of three phase machines to extract the best performance. It proposes a novel method for improving performance of a Single Phase Induction Motor using indirect current control of VSI with dynamic capacitor. Normally a fixed capacitor is included in the auxiliary winding in order to make a phase angle difference of $90^{\circ}$ between main and auxiliary windings. Instead of using a fixed capacitor, in the proposed approach, a dynamic capacitor is included with the auxiliary winding to make the two winding currents always in $90^{\circ}$ phase quadrature irrespective of the load conditions [6].

The efficiency optimization of wound rotor induction motor using soft computing techniques has been presented in [14].

This paper proposes a novel technique of using a VSI with a Hbridge dynamic capacitor in the rotor circuit in order to improve the performance of the wound rotor induction motor. The 
proposed scheme uses only one capacitor with a three phase VSI bridge.

\section{ROTOR IMPEDANCE CONTROL SCHEME}

\subsection{Switched Capacitor principle}

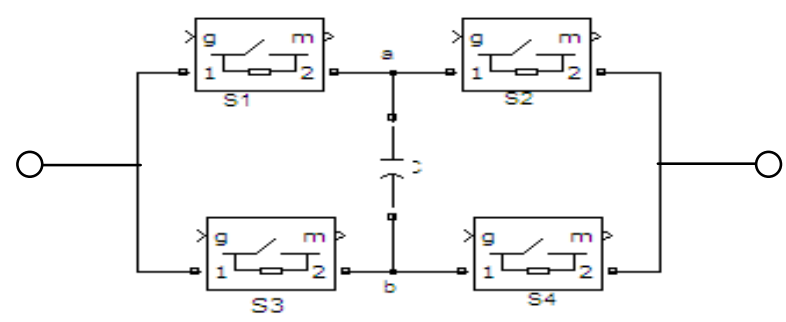

Fig.1. Basic H Bridge Switch with an ac capacitor

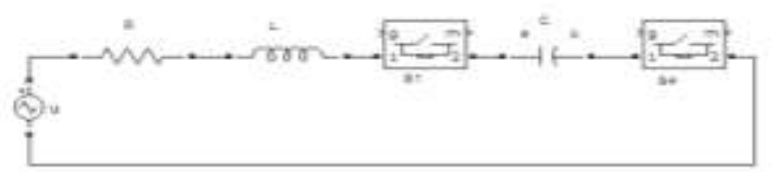

(a)

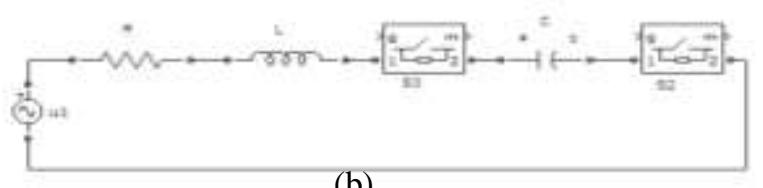

(b)

Fig.2 RL circuit with switched capacitor during time interval $t_{1} b$ ) during time interval $t_{2}$-discharging

In [4], the author describes the switched capacitor concept which is used to improve the power factor of the inductive circuit. It consists of placing an ac capacitor in the middle of an $\mathrm{H}$ bridge with bi-directional switches as shown in Fig.1. The complementary switch pairs (S1, S4) and (S2, S3), respectively, are switched using a PWM strategy.

This structure is conceived to control the phase of the current in power inductive circuits. During time interval, the switch pair (S1, S4) is ON the capacitor is charging and a serial RLC circuit is modelled.

In the time interval, the switch pair (S2, S3) is ON the capacitor is applied with reverse polarity to the RL circuit and the capacitor starts discharging.

$\mathrm{t} 1+\mathrm{t} 2=\mathrm{T}$

$\mathrm{d}=\frac{\mathrm{t}_{1}}{\mathrm{~T}}$

In this way the effective value of the capacitance is given by

$$
\mathrm{C}_{\mathrm{e}}=\mathrm{C} /(2 \mathrm{~d}-1)^{2}
$$
$\mathrm{C}_{\mathrm{e}}$ - Effective capacitance value
C - External Capacitance
d - Duty ratio of the H-bridge switch

The switched capacitor concept is adopted in the proposed method to change the capacitance value dynamically rotor circuit of proposed method.

\subsection{Switched Capacitor in the Rotor Circuit}

In [5], the switched capacitor concept has been used in the rotor circuit of the wound rotor induction motor as shown in the Fig. 3. In this method, $\mathrm{H}$-bridge switched capacitors are connected in each phase of the rotor circuit. The duty ratio of the capacitor circuit is varied in order to change the effective rotor capacitance value. The various performance parameters such as efficiency, power factor are found with respect to variation of slip and duty ratios. This scheme is employed in the rotor circuit of a three phase wound rotor induction motor in order to enhance the performance parameters of the motor.

The expressions for Torque $\left(\mathrm{T}_{\mathrm{m}}\right)$, input $(\mathrm{P}) \&$ output power $\left(\mathrm{P}_{\mathrm{m}}\right)$, efficiency and power factor values are derived from [5], [11] \& [12] and given below.

$$
\begin{aligned}
& \mathrm{P}=\operatorname{Re}(\bar{S})=\frac{3}{2} \frac{\mathrm{u}_{\mathrm{S}}^{2}\left(\mathrm{R}_{\mathrm{r}} V_{\mathrm{m}}+\omega_{\mathrm{z}} W_{\mathrm{m}}\left(\mathrm{L}_{\mathrm{r}}-\frac{1}{\omega_{2}^{2} \mathrm{C}_{\mathrm{r}}}\right)\right.}{V_{\mathrm{m}}^{2}+W_{\mathrm{m}}^{2}} \\
& \mathrm{Q}=\operatorname{Im}(\bar{S})=\frac{3}{2} \frac{\mathrm{u}_{\mathrm{S}}^{2}\left(\mathrm{R}_{\mathrm{r}} W_{\mathrm{m}}-\omega_{\mathrm{z}} V_{\mathrm{m}}\left(\mathrm{L}_{\mathrm{r}}-\frac{1}{\omega_{2}^{2} \mathrm{C}_{\mathrm{r}}}\right)\right.}{V_{\mathrm{m}}^{2}+W_{\mathrm{m}}^{2}}
\end{aligned}
$$

Where

$$
\begin{aligned}
& \mathrm{V}_{\mathrm{m}}=\mathrm{R}_{\mathrm{a}} \mathrm{R}_{\mathrm{r}}+\omega_{1} \omega_{2} \mathrm{~L}_{\mathrm{m}}^{2}-\omega_{1} \omega_{2} \mathrm{~L}_{\mathrm{a}}\left(\mathrm{L}_{\mathrm{r}}-\frac{1}{\omega_{\mathrm{r}}^{\mathrm{n}} \mathrm{C}_{\mathrm{r}}}\right) \\
& \mathrm{W}_{\mathrm{m}}=\omega_{1} \mathrm{~L}_{\mathrm{a}} \mathrm{R}_{\mathrm{r}}+\omega_{2} \mathrm{R}_{\mathrm{g}}\left(\mathrm{L}_{\mathrm{r}}-\frac{1}{\omega_{2}^{2} \mathrm{C}_{\mathrm{r}}}\right)
\end{aligned}
$$

Thus the Power factor $\cos \Phi_{1}$ and efficiency $\eta$ may be estimated from

$$
\begin{aligned}
& \operatorname{Cos} \Phi 1=\frac{p}{\sqrt{p^{2}+Q^{2}}} \\
& \eta=\frac{p_{W}}{p}
\end{aligned}
$$

Where

$$
P_{U}=t_{g} \frac{w_{1}-w_{2}}{p}
$$

The expression for torque as function of speed is derived as

Here in (2), 


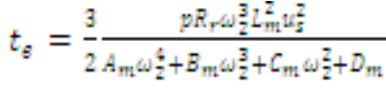

Where

$\mathrm{u}_{\mathrm{s}}$ Space phasor stator voltage

$R_{s}, R_{r} \quad$ Stator resistance and rotor resistance respectively

$\mathrm{L}_{\mathrm{S}}, \mathrm{L}_{\mathrm{r}}$ Stator inductance and rotor inductance respectively

$\omega_{1}, \omega_{2} \quad$ Angular velocity of Rotor and Stator circuit

$\mathrm{t}_{\mathrm{e}} \quad$ Electromagnetic Torque

$\mathrm{P}_{\mathrm{M}}, \mathrm{P}, \mathrm{Q}$ Mechanical, Active and Reactive power

$\mathrm{p} \quad$ Number of poles

\subsection{Rotor Impedance Control}

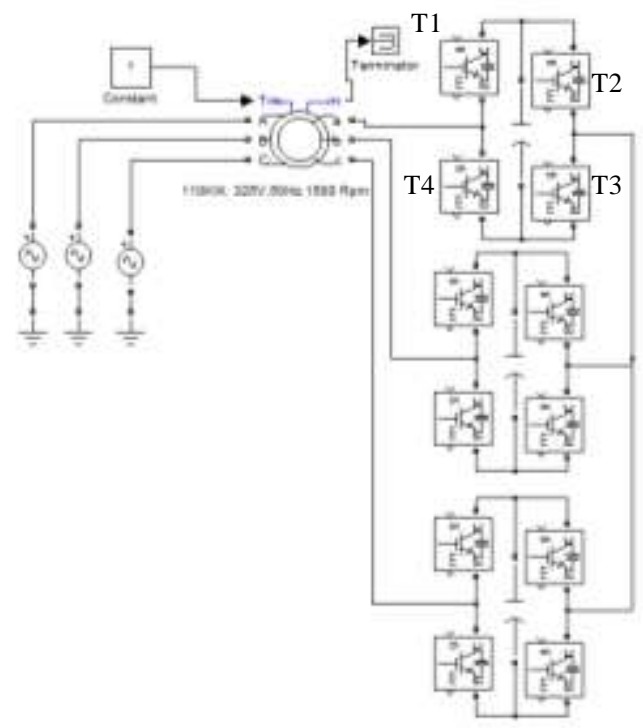

Fig.3 Circuit diagram of rotor impedance control

The Fig.3 shows the simulation circuit diagram of rotor impedance control scheme of the three phase induction motor. The stator is connected to three phase AC supply and each phase of the rotor is connected to H-Bridge with a capacitor placed in the middle of the H-bridge circuit. The capacitor is charging while the thyristors $\mathrm{T} 1$ and $\mathrm{T} 3$ is conducting. The capacitor starts discharging when the thyristors $\mathrm{T} 2$ and $\mathrm{T} 4$ conducting. The same switching action is performed in each phase of the rotor circuit.

In the secondary impedance control scheme, totally three numbers of H-bridges switches (4 switches for each H-bridge) with three capacitors have been used. In this scheme, as more number of switches and capacitors are used, this may suffer from switching losses and become less cost effective. In order to overcome these drawbacks, the proposed method has been adopted with less number of switches and a single capacitor in order to improve the motor performances.

\section{PROPOSED VSI WITH DYNAMIC CAPACITOR CONTROLLED ROTOR CIRCUIT}

\subsection{System Description}

In the proposed scheme, only one $\mathrm{H}$-bridge switch with a capacitor and a VSI bridge circuit have been used. The number of components used in the proposed scheme is less compared with conventional secondary impedance control scheme. This also further reduces the switching losses.

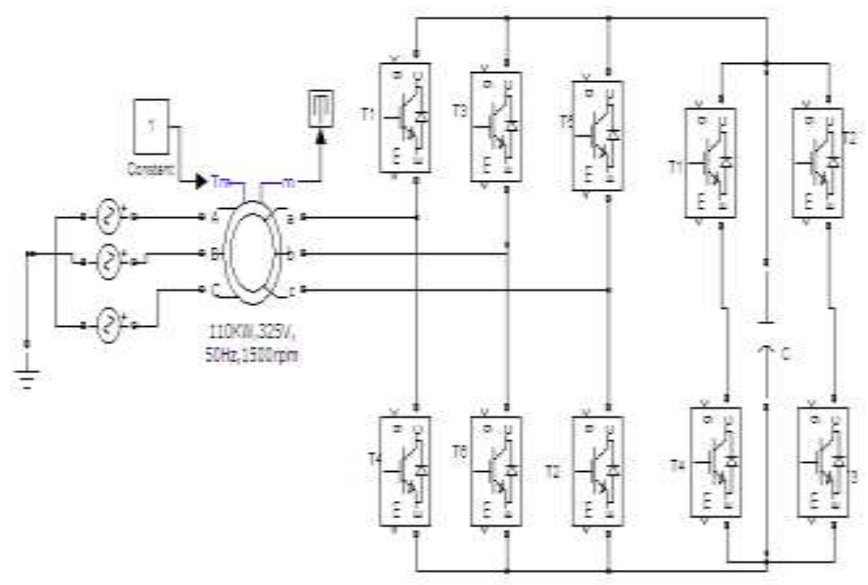

Fig.4 Proposed Simulation Circuit of VSI with Dynamic Capacitor controlled rotor circuit

The Fig.4 shows the proposed VSI with dynamic capacitor controlled Rotor impedance control. The Stator is given to the three phase supply and the rotor is fed three phase bridge inverter with a dynamic capacitor which emulates the variable capacitor. The duty ratio of the $\mathrm{H}$-bridge circuit is varied in order to change the dynamic capacitor value according to equation (2). The duty ratio and frequency of the VSI bridge can be changed in order to work the induction motor at different slip speeds.

The performance parameters such as efficiency, power factor values with respect to duty ratios and slip at different loading conditions are obtained using Matlab simulations. The table 1 describes the varies simulation parameters of induction motor used for simulation.

Table 1 Simulation parameters

\begin{tabular}{|l|l|}
\hline Motor Rating & $110 \mathrm{KW}$ \\
\hline Voltage & $325 \mathrm{~V}$ \\
\hline Frequency & $50 \mathrm{~Hz}$ \\
\hline Stator Resistance & $0.126 \Omega$ \\
\hline Stator Inductance & $0.0013 \mathrm{mH}$ \\
\hline Rotor Resistance & $0.118 \Omega$ \\
\hline Rotor inductance & $0.00137 \mathrm{mH}$ \\
\hline Mutual Inductance & $0.0583 \Omega$ \\
\hline No.of poles & 4 \\
\hline
\end{tabular}

\section{SIMULATION RESULT AND DISCUSSIONS}

In this proposed method the external rotor circuit is connected to three phase bridge inverter which makes use of six switches and a $\mathrm{H}$-bridge with a single capacitor. But in the existing secondary 
impedance control method, the external rotor circuit uses four switches and a capacitor in each phase (Totally 12 switches) and 3 capacitors which increase the switching losses and overall cost, thereby reducing the system efficiency. Simulation circuit is as shown in Fig. 12

\subsection{Simulation Result}

$\mathrm{I}_{\mathrm{r}}$

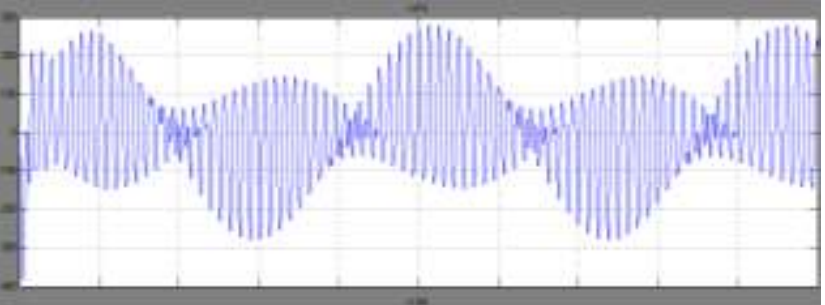

$\mathrm{I}_{\mathrm{s}}$

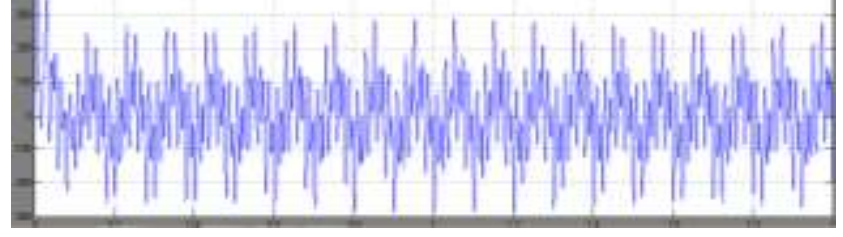

Time

Fig.5 Output Waveform of $I_{r}, I_{s}$

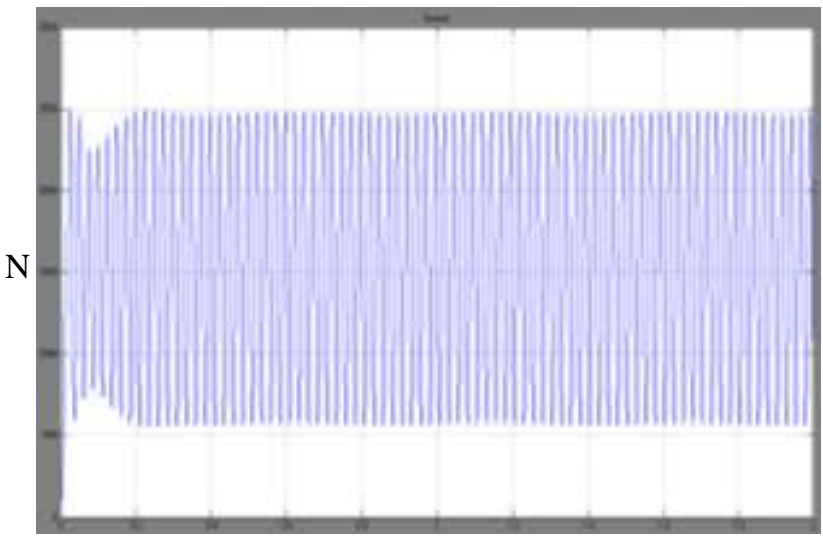

Time

Fig.6 Speed Waveform

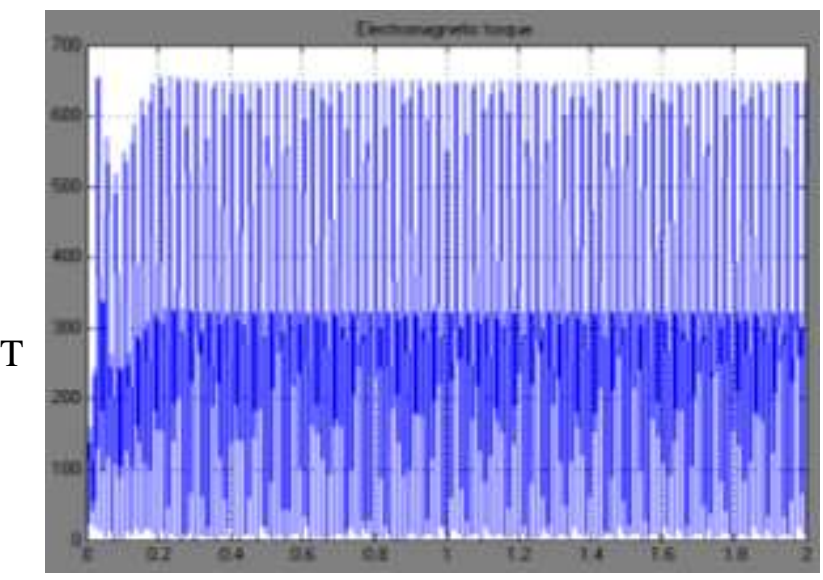

Time

Fig.7 Torque Waveform

\section{COMPARISON PERFORMANCES OF INDUCTION MOTOR PROPOSED METHOD AND EXISTING METHOD}

The comparison of both proposed and existing method is done. The result shows that the performance parameters like power factor and efficiency are improved in proposed method compared to that of the existing method. There is a significant improvement in efficiency and power factor by order of $8-10 \%$. In existing method it uses four thyristors and a capacitor in each rotor phase, so totally it utilizes twelve thyristors and three capacitors. In proposed method it uses totally a six thyristors and a capacitor in the rotor side. It reduces switching losses thereby increasing the system efficiency.

The tables 2, 3, $4 \& 5$ and the graphs Fig.8, 9, $10 \& 11$ show the comparison of various performance parameters of proposed and existing rotor impedance control schemes for different slip and loading conditions.

\subsection{Performance curve as variation of Duty Ratio}

Table 2 Power factor for different duty ratio

\begin{tabular}{|c|c|c|}
\hline $\begin{array}{c}\text { Duty } \\
\text { Ratio }\end{array}$ & $\begin{array}{l}\text { Power factor } \\
\text { value of Proposed } \\
\text { method }\end{array}$ & $\begin{array}{c}\text { Power factor value } \\
\text { of Conventional } \\
\text { method }\end{array}$ \\
\hline 0.55 & 0.87 & 0.85 \\
\hline 0.6 & 0.92 & 0.85 \\
\hline 0.65 & 0.91 & 0.89 \\
\hline 0.7 & 0.91 & 0.83 \\
\hline 0.75 & 0.92 & 0.85 \\
\hline 0.8 & 0.88 & 0.85 \\
\hline
\end{tabular}

Table 3 Efficiency for different duty ratio

\begin{tabular}{|c|c|c|}
\hline $\begin{array}{c}\text { Duty } \\
\text { Ratio }\end{array}$ & $\begin{array}{c}\text { Efficiency } \\
\text { value of } \\
\text { Proposed } \\
\text { method }\end{array}$ & $\begin{array}{c}\text { Efficiency value of } \\
\text { Conventional method }\end{array}$ \\
\hline 0.55 & 69.64 & 47.38 \\
\hline 0.6 & 88.15 & 61.77 \\
\hline 0.65 & 65.65 & 58.32 \\
\hline 0.7 & 62.94 & 56.93 \\
\hline 0.75 & 66.14 & 55.54 \\
\hline 0.8 & 69.68 & 59.93 \\
\hline
\end{tabular}




\subsection{Performance curve as variation of Load}

Table 4 Power factor for different Load values

\begin{tabular}{|c|c|c|}
\hline $\begin{array}{c}\text { Load } \\
\text { values }\end{array}$ & $\begin{array}{c}\text { Power factor } \\
\text { value of } \\
\text { Proposed } \\
\text { method }\end{array}$ & $\begin{array}{l}\text { Power factor value } \\
\text { of Conventional } \\
\text { method }\end{array}$ \\
\hline 50 & 0.32 & 0.45 \\
\hline 100 & 0.86 & 0.86 \\
\hline 150 & 0.45 & 0.38 \\
\hline 200 & 0.42 & 0.28 \\
\hline 250 & 0.68 & 0.59 \\
\hline 300 & 0.85 & 0.65 \\
\hline
\end{tabular}

Table 5 Efficiency for different Load values

\begin{tabular}{|c|c|c|}
\hline $\begin{array}{c}\text { Load } \\
\text { values }\end{array}$ & $\begin{array}{c}\text { Efficiency } \\
\text { value of } \\
\text { Proposed } \\
\text { method }\end{array}$ & $\begin{array}{l}\text { Efficiency value of } \\
\text { Conventional } \\
\text { method }\end{array}$ \\
\hline 125 & 5.96 & 16.26 \\
\hline 150 & 23.07 & 30.78 \\
\hline 175 & 35.46 & 42.11 \\
\hline 200 & 42.65 & 49.09 \\
\hline 225 & 47.70 & 58.54 \\
\hline 250 & 62.44 & 59.28 \\
\hline
\end{tabular}

\subsection{Comparison Graph}

\subsubsection{Power Factor curve}

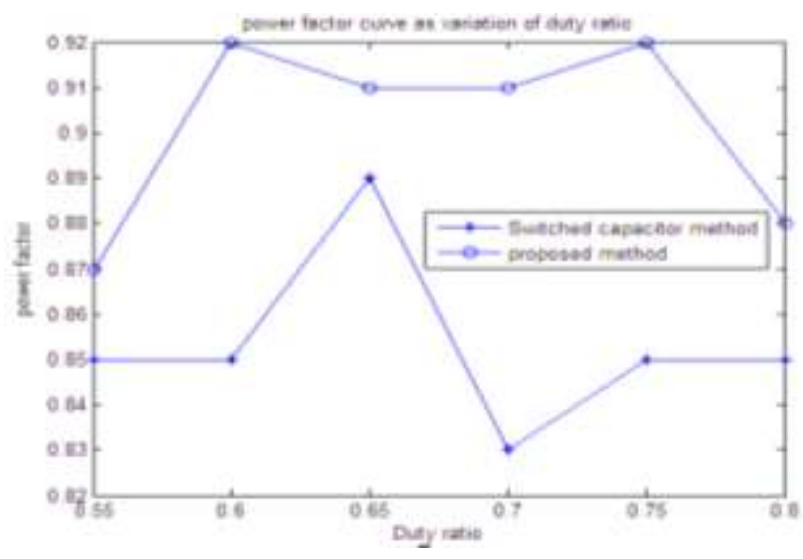

Fig.8 power factor curve

\subsubsection{Efficiency curve}

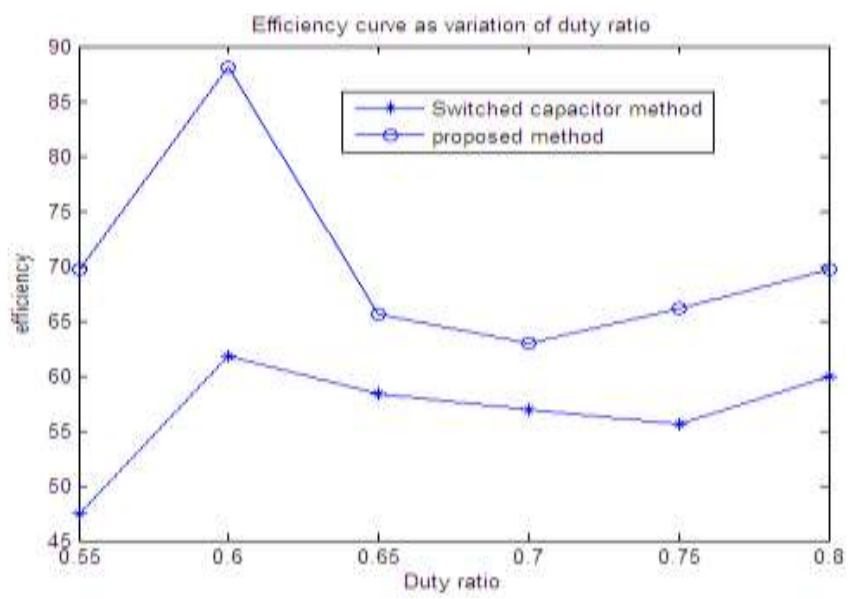

Fig.9 efficiency curve

\subsubsection{Power factor curve as variation of load}

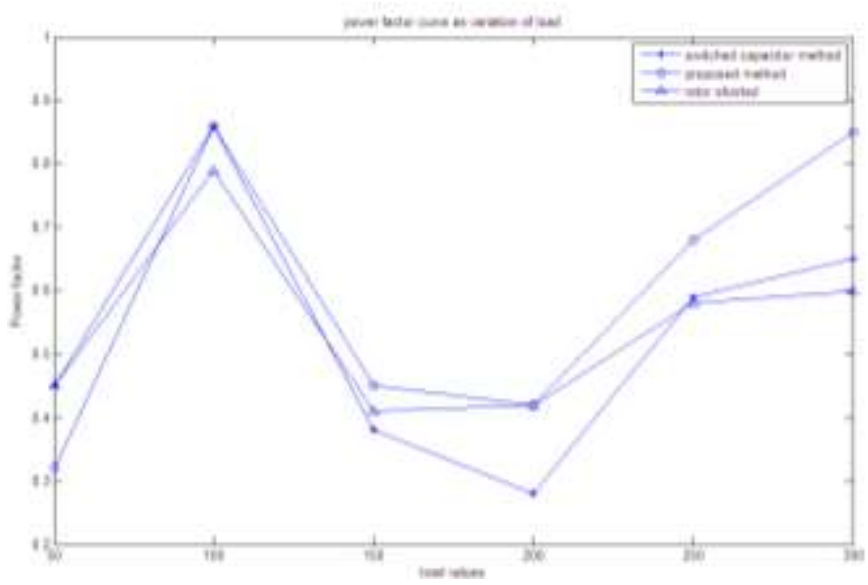

Fig.10 Power factor curve

\subsubsection{Efficiency curve as variation of load}

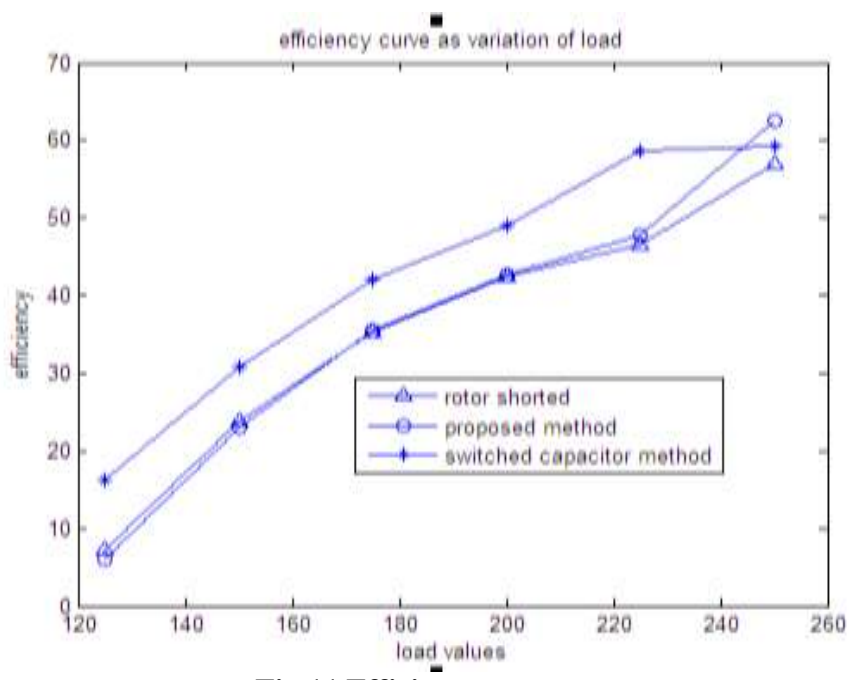

Fig.11 Efficiency curve 


\section{CONCLUSION}

The proposed scheme is simulated for different slip and loading conditions by varying the duty ratios in order to emulate the dynamic capacitor values for obtaining the improved performance parameters such as efficiency and power factor of induction motor. The comparative study of the proposed scheme with rotor impedance control scheme shows better improvements in the performance parameters. As the proposed scheme uses reduced external switching components and only a single capacitor, significant reduction of cost in overall control circuit can be achieved. In addition to this, it also further reduces the switching losses.

As a future work, a better control scheme can be implemented with expert systems such as fuzzy and neural network for controlling the switching circuit and obtaining optimum efficiency and power factor at all loading and slip conditions. The torque pulsations and harmonics caused due to switching in the rotor circuit have not been considered in this paper which may be addressed in future work.

\section{REFERENCES}

[1]. Y. Baghouz and O. T. Tan, "Optimal efficiency speed control of induction motors by variable rotor impedance," IEEE Trans. Energy Conv., vol. 4, pp. 216-223, June 1989.

[2]. Dr.Saeed lesan and William shepherd, " Control of Wound rotor induction motor with rotor impedance variation", IEEE Trans, 1993

[3]. J. Reinert and M. J. Parsley, "Controlling the speed of an induction motor by resonating the rotor circuit," IEEE Trans. Ind. Applicat., vol. 31, pp. 887-891, July/Aug. 1995

[4]. C. Suciu, L. Dafinca, M. Kansara, and I. Margineanu, "Switched capacitor fuzzy control for power factor correction in inductive circuits," in Proc. IEEEPESC, vol. 2, Galway, pp. 773-777, 2000

[5]. Constantin Suciu, Mohan Kansara, Peter Holmes, and Wilibald Szabo, Member, IEEE, "Performance Enhancement of an Induction Motor by Secondary Impedance Control", IEEE transcations on Energy conversion, Vol.17, No 2, June 2002
[6]. Vishal Verma, Peeyush Pant,Bhim Singh, "Simulation of Single Phase Induction Motor With Dynamic Capacitor For Maximum Torque Operation", IEEE International Electric Machines and Drives Conference, 2008.

[7]. D.W. Novotny, T. A. Lettenmaier and T. A. Lipo, "Single-Phase Induction Motor With an Electronically Controlled Capacitor", IEEE Trans. Ind Application, Vol. 27, pp. 38 - 43, Jan/Feb 1991,

[8]. P.N Enjeti and A.Rahman, "A New Single-Phase to Three Phase Converter with Active Input Current Shaping for Low Cost Ac Motor Drives", in conf.Rec.IEEE-IAS Annu Meeting, pp. 935 - 939, 1983

[9]. E. Muljadi, Y. Zhao, T. Liu and T.A. Lipo, “Adjustable ac Capacitor for a Single-phase Induction Motor", IEEE Transactions on Industry Applications, Vol. 29, No. 3, pp.479 - 485, May/June 1993

[10]. D. Jang and D. Yoon, "Space Vector PWM Technique for Two-Phase Inverter-Fed Single-phase Induction Motors", in Proc. of IEEE Conference, pp. 47 - 53, 1999

[11]. C.Suciu, M.Kansara, P.G.Holmes, "A Space vector model of a static leading VAR secondary controlled induction machine", in Proc. of OPTIM '98, pp- 375379, May 1998

[12]. H.Salama, M.kansara, P.G.Holmes, Y.Safar, , "Optimal Steady state performance of induction motor drives", in Proc. of OPTIM' 96, pp- 1347-1360, May 1996

[13]. M.F.Rahman, L.Zhong, "Single Phase Regenerative Variable Speed Induction Motor Drives". in Proc. of EPE conf, pp. 3773 - 3780, 1995

[14]. K.Ranjith kumar, S.Palaniswami, D.Sakthibala, "Efficiency Optimization of Induction Motor Drive Using Soft Computing Techniques", International Journal of Computer Applications, Vol. 3, No.1, pp. 6-12, June 2010

[15]. P.V Anada, V.Ramachandran, M.N.S. Swamy, "Switched capacitors Filters", 1995 


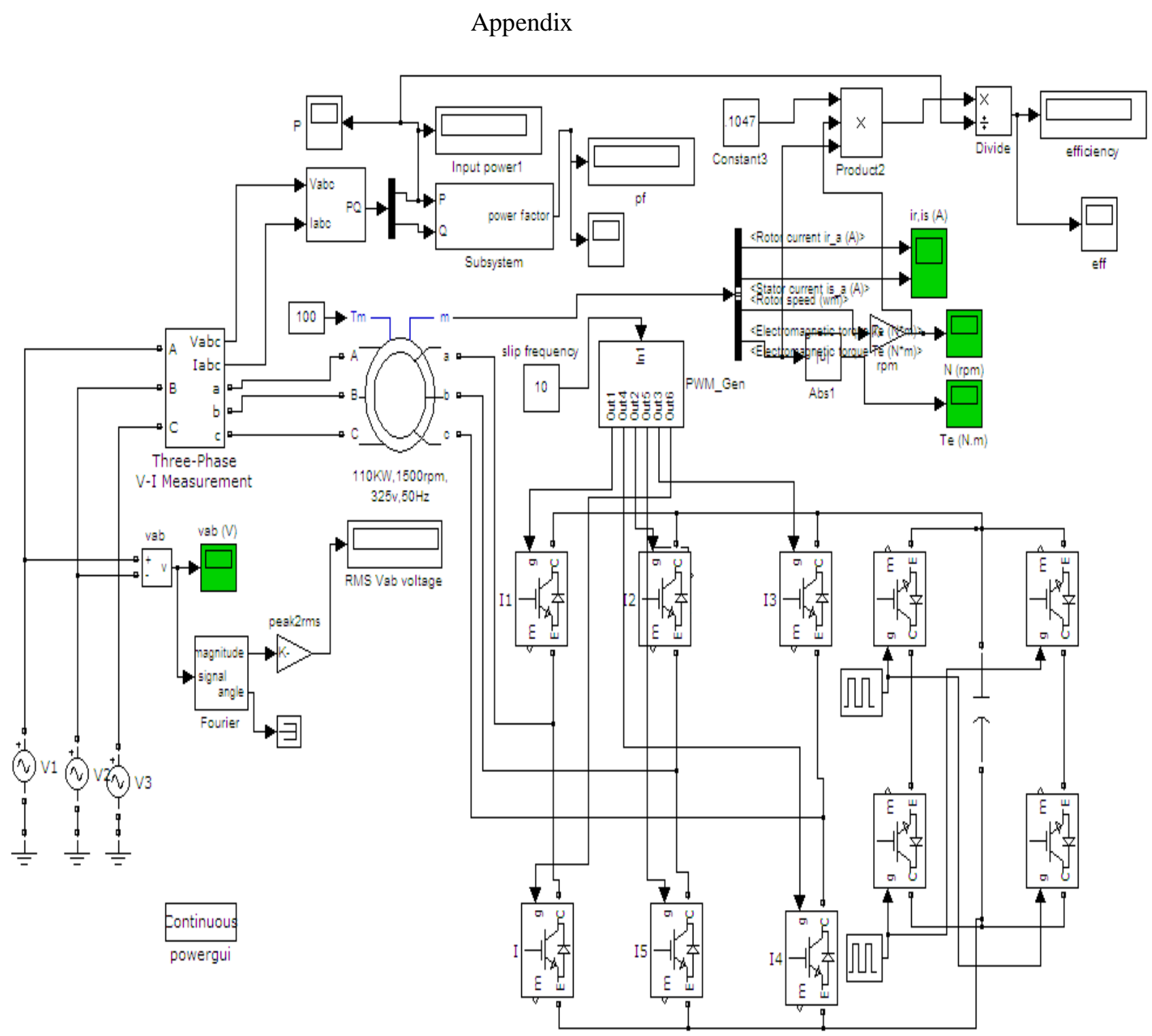

Fig.12 Simulation circuit of proposed method 